\title{
A Misunderstanding of Moral Distress
}

Lucia D. Wocial, PhD, RN, FAAN

Fairbanks Center for Medical Ethics, Indiana University Health, Indiana University School of Nursing

\author{
Word Count: $1537^{*}$ \\ Lucia D. Wocial \\ Fairbanks Center for Medical Ethics \\ Methodist Hospital \\ 1800 N Capitol Ave \\ Noyes Pavilion, E-130 \\ Indianapolis, IN 46202 \\ 317-962-2161
}

1wocial@iuhealth.org

*(1563 with citations see page 4$)$

This is the author's manuscript of the article published in final edited form as:

Wocial, L. D. (2016). A Misunderstanding of Moral Distress. The American Journal of Bioethics, 16(12), 21-23. https://doi.org/10.1080/15265161.2016.1239791 


\section{A Misunderstanding of Moral Distress}

Campbell, Ulrich and Grady (2016) should be commended for attempting to contribute to the discussion of what many believe is currently a messy concept. They propose that a broader definition of moral distress is desirable and offer up a new one. Sadly, despite their acknowledgment of caution from previous authors, their proposed definition is so broad that it is diagnostically and analytically meaningless. The authors' vague definition (p. 15) "one or more negative self-directed emotions or attitudes that arise in response to one's perceived involvement in a situation that one perceives to be morally undesirable" reduces the experience of moral distress to feeling bad because one is caught in a morally undesirable situation.

Moral distress is a feeling that has moral meaning. The sense that one has a responsibility to act is based on professional obligations. It is a feeling in response to a failed action in an ethically challenging situation. It is much more than feeling badly or simply being involved in a morally undesirable situation. The authors' recommendation that when "the distress springs from obviously misguided moral views or unreasonable beliefs about one's involvement" (p. 22) it might be best to let individuals address the feelings on their own is misguided. This attitude implies disdain for an individual who may be developing their ethical sensitivity in practice. How is one to gain insight without seeking assistance in exploring the nature of one's feelings?

It is unfortunate that the authors suggest moral distress can be whatever the author means it to be (Campbell, Ulrich and Grady, 2016 P.3). For the person experiencing it, moral distress is real however to say one has moral distress is not enough. Denise Dudzinski's recent article (2016) provides an excellent map for dissecting an emotional experience thought to be moral distress. Had the authors focused their attention on the special features of moral distress explicated by Dudzinski instead of three elements, it might have become clear that their six cases do not offer any clarity for their definition or support their argument that a broader definition of moral distress is desirable.

The authors' use of cases does not serve their purpose well. While some of the examples describe situations that have an impact on the moral experience of individuals, others fit into the 
current definition of moral distress and thus do not require a new definition. Space does not allow for a point by point discussion of the authors' six cases so I will address what I feel are the most problematic. In their example of why moral uncertainty should be included in a definition of moral distress the authors' use the example of a surgeon questioning the practice of assigning him as the junior surgeon to patients with complex medical conditions. The surgeon is experiencing some self-doubt and concern that he is harming patients. One has to ask, is this a matter of conscience or confidence? He considers two options that are arguably political not moral choices. He is anticipating reasons why not to pursue an action. Inaction would be a problem.

Even if the surgeon does not know exactly what is the correct course of action, he recognizes a sense of responsibility, feels powerless, is concerned for patient well-being, believes there is personal risk regardless of the path chosen and to do nothing simply to protect himself would compromise his integrity. Failing to pursue the counsel of someone who could offer a different perspective on his feelings (inaction) would be the problem in this scenario. His experience of moral distress is complicated by his uncertainty about what to do. His struggle represents an internal constraint and could easily fall into the current understanding of moral distress. No new definition is needed for this case.

The second example is particularly troubling. To state that the nurse in this scenario is only mildly distressed is no doubt plausible however the action (or inaction in this case) is motivated by self-interest and contrary to provisions in the Code of Ethics for Nurses (ANA, 2015). The authors imply that because examples in the literature of moral distress are often dramatic that this somehow indicates all moral distress is intense and extreme and go so far to suggest that mild moral distress has a lower moral priority than stronger forms of distress. Nowhere in the literature does any author suggest that mild moral distress has lower moral priority or that it should not be considered important.

There are two instruments designed to measure moral distress currently in use and both ask respondents to indicate their degree (intensity) of distress (MDS-R Hamric, Borchers \& Epstein, 2012: and MDT Wocial \& Weaver, 2013). By using an example of "mild distress" to suggest 
that it somehow justifies a different definition of moral distress illustrates the authors' unsophisticated understanding of the published literature on moral distress. Not every episode of moral distress is dramatic, nor does any current definition suggest this. The focus on high levels of distress is because there are numerous examples in the literature that provide evidence that high levels have significant negative consequences (Allen et al, 2013: Houston, et al, 2013; Lamiani, Berghi \& Argentero, 2015; McAndrew, Leske, \& Garcia, 2011; Whitehead, et al 2015; Wilson, et al, 2103).

The case example used to convince the reader that a moral dilemma should somehow be included in a new definition of moral distress is a mistake. What the parents ask of the clinicians is contrary to best practice in pediatrics. The authors' do not discuss assent which is a crucial concept to consider in the situation they describe. The revelation that the bioethicist would advise the team to disclose to the patient the extent of his diagnosis suggests that the bioethicist is unfamiliar with pediatrics. In this case the bioethicist should be troubled, not because of a moral dilemma but because he failed to do due diligence to identify an alternate path, for example engaging the patient in a discussion about how much he wants to know about his disease and informing the parents that children often ask and clinicians should never be put in a position to lie to the patient. Using this case undermines the authors' effort to convince the reader that moral dilemmas should be included in their umbrella term for moral distress. Many who do ethics consultation recognize that the presence of moral distress is an indication of a moral dilemma.

The introduction of the term bad moral luck is concerning. The psychiatrist is obsessing about a patient's actions which were completely beyond his control. Would he obsess equally if he failed to provide the medication and the patient shot himself? Bad outcomes for patients are not moral failings of providers. Bad moral luck implies there is moral taint when a provider cares for a patient and the outcome for the patient is undesirable. If this were the case, the emotional burden on providers would be paralyzing. Unfortunate patient outcomes do not mean a morally bad choice was made. 
The delayed distress example is intriguing. In the moment, the physician acts according to the standard of care. On reflection, he has some uncertainty about whether or not he did the correct thing, based on concerns about the patient's future quality of life if she survives. There was no constraint on his actions at the time of the resuscitation. His reflections may, likely will guide his future clinical practice and as a physician he will likely be able to exercise his clinical judgment and alter his clinical approach (stop resuscitation attempts sooner). As described, rather than delayed distress, I might argue that the event led to increased moral sensitivity and reflection on practice. Why try to lump this experience into a definition of moral distress? Why not create a different taxonomy with moral distress a part of the moral experience and moral reflection another part?

Finally, suggesting that there is something called anticipatory distress and that it should be included in a definition of moral distress is absurd. What use is this idea? Of course each of us should expect to find ourselves in morally compromising situations because they happen every day. We should anticipate moral stress and use that to prepare ourselves for how we will act in the moment. That is why we learn codes of ethics, practice guidelines, policies and procedures.

\section{Summary}

The authors use case examples that illustrate different types of moral work in an effort to argue that they describe things that should be included in a definition of moral distress. Hard moral work is not the same as moral distress. Perhaps the authors should propose a broader term (e.g. a troubled conscience) that includes moral distress in the taxonomy. The great contribution of the authors' essay is that it drives home the point that naming something moral distress does not make it so. When one feels one has moral distress, the best course of action is to discuss the feelings with someone who can help that individual conduct an analysis of the experience to uncover the ethical nature of the problem. The proposed broader definition of moral distress is not workable or desirable. The essay by Campbell, Ulrich and Grady provides an opportunity to explore what moral distress is and is not and since the construct has gained such importance, their essay likely will contribute to further efforts to define the construct. 
Referencec

Allen, R., Judkins-Cohn, T., deVelasco, R., Forges, E., Lee, R., Clark, L., et al. (2013). Moral distress among healthcare professions at a health system. JONA'S Healthcare Law, Ethics and Regulation, 15, 111-118.

Dudzinski, D. M. (2016). Navigating moral distress using the moral distress map. Journal of Medical Ethics 42(5), 1-4. DOI: 10.1136/medethics-2015-103156

Hamric A. B., Borchers, C. T., \& Epstein, E. G. (2012). Development and testing of an instrument to measure moral distress in health care professionals. AJOB Primary Research, 3(2), 1-9.

Houston, S., Casanova, M. A., Leveille, M., Schmidt, K. L., Barnes, S. A., Trungale, K. R., \& Fine, R. L. (2013). The intensity and frequency of moral distress among different healthcare disciplines. J Clin Ethics. 24(2), 98-112.

Lamiani, G, Borghi, L \& Argentero, P. (2015). When healthcare professionals cannot do the right thing: A systematic review ofmoral distress and its correlates. Journal of Health Psychology, 1-17. doi: 10.1177/1359105315595120

McAndrew, N. S., Leske, J. S., \& Garcia, A. (2011). Influence of Moral Distress on the Professional Practice Environment During Prognostic Conflict in Critical Care. Journal of Trauma Nursing: 18(4): pp. 221-230. doi: 10.1097/JTN.0b013e31823a4a12

Whitehead, P. B., Herbertson, R. K., Hamric, A. B., Epstein, E. G., and Fisher, J. M. ( 2015). Moral distress among healthcare professionals: report of an institution-wide survey. Journal of Nursing Scholarship 47(2), 117-25. doi: 10.1111/jnu.12115. Epub 2014 Nov 29.

Wilson, M. A, Goettemoeller, D. M., Bevan, N. A., \& McCord, J. M. (2013). Moral distress: levels, coping and preferred interventions in critical care and transitional care nurses. $J$ Clin Nurs. 22(9-10):1455-66. doi: 10.1111/jocn.12128. Epub 2013 Mar 8.

Wocial, L. D. \& Weaver, M. T. (2013). Evaluation of a new tool for Measuring Moral Distress: The Moral Distress Thermometer. J Adv Nurs. 69(1), 167-74. doi: 10.1111/j.13652648.2012.06036.x. 